\title{
Article
}

\section{A Qualitative Description of Community Service, Business and Organization Perspectives on Mental Illness and Inclusion}

Kidd, S.A., Frederick, T, Tarasoff, L, Virdee, G, Lurie, S, Davidson, Lesley, Morris, David and McKenzie, K

Available at http://clok.uclan.ac.uk/16106/

Kidd, S.A., Frederick, T, Tarasoff, L, Virdee, G, Lurie, S, Davidson, Lesley, Morris, David ORCID: 0000-0001-7372-8084 and McKenzie, K (2017) A Qualitative Description of Community Service, Business and Organization Perspectives on Mental IIIness and Inclusion. American Journal of Psychiatric Rehabilitation, 20 (4). pp. 327-345. ISSN 1548-7768

It is advisable to refer to the publisher's version if you intend to cite from the work. http://dx.doi.org/10.1080/15487768.2017.1374219

For more information about UCLan's research in this area go to http://www.uclan.ac.uk/researchgroups/ and search for <name of research Group>.

For information about Research generally at UCLan please go to http://www.uclan.ac.uk/research/

All outputs in CLoK are protected by Intellectual Property Rights law, including Copyright law. Copyright, IPR and Moral Rights for the works on this site are retained by the individual authors and/or other copyright owners. Terms and conditions for use of this material are defined in the policies page. 


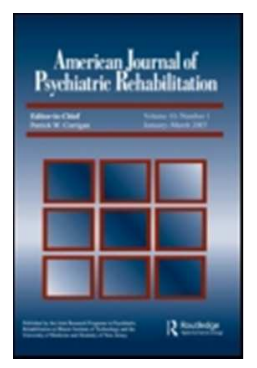

\section{A qualitative description of community service, business, and organization perspectives on mental illness and inclusion}

\begin{tabular}{|r|l|}
\hline Journal: & American Journal of Psychiatric Rehabilitation \\
\hline Manuscript ID & UAPR-2015-0025.R2 \\
\hline Manuscript Type: & Original \\
\hline Keywords: & schizophrenia, severe mental illness, community, public, inclusion, stigma \\
\hline \multicolumn{2}{|c}{} \\
\hline
\end{tabular}

\section{SCHOLARONE ${ }^{m}$}

Manuscripts

URL: https://mc.manuscriptcentral.com/ajpr Email: stephanie.sangsterlanteri@yale.edu 


\begin{abstract}
While stigma associated with mental illness is pervasive, less is known about community stakeholder perspectives on inclusion and exclusion. This study provides a qualitative analysis of the mental-illness related experiences and perspectives of individuals who form much of the fabric of 'community' for individuals with severe mental illness. In-depth interviews were conducted with a diverse group of 94 key community stakeholders in 5 neighbourhoods in a large Canadian urban centre. Qualitative analysis revealed a range of strategies that were used to foster inclusive spaces, the dilemmas that attended more severe forms of mental illness, and the importance of the meanings ascribed to mental illness in determining responses. revealed emphases placed upon positioning mental illness in determining responses, efforts made to foster inclusive spaces, and the dilemmas that attend more severe representations of mental illness in eommunity spaces.-Differences in response as a function of stakeholder group were also explored. There exist very promising resources and diverse perspectives on inclusion in urban communities that warrant further investigation given the intensive emphasis upon 'community' in policy and practice dialogues.
\end{abstract}

Keywords: schizophrenia; severe mental illness; community; public; inclusion; stigma 
Research into public views about mental illness have generally concentrated on prevalence and factors associated with a desire for social distance, such as considering mental illness as a brain disease (Angermeyer, Beck \& Matschinger, 2003) and type of illness or label, with schizophrenia and addictions prompting the strongest responses (Parcasepe \& Cabassa, 2013; Stuber, Rocha, Christian \& Link, 2014). The study of the experiences of people with mental illness have highlighted the very distressing nature of dominant stigmatizing messages and associated structural forms of discrimination. This work has highlighted the manner in which stigma greatly affects social interactions leading to social isolation and ongoing fear of exclusion and discrimination (Mestdagh \& Hansen, 2014). 
A small number of studies have examined the perspectives of community members who do not identify as having a mental illness in more depth. In one qualitative study of the perceptions of community members, it was noted that to a large extent what triggered labeling had to do with people's appearance and behavior (Flanagan \& Davidson, 2009). Specifically, participants noted that responding to internal stimuli and dress that was considered bizarre or inappropriate were the primary indicators of severe mental illness. Regular exposure, however, tended to lead to "compassion" or "pity" rather than the fear and discomfort typically attending stigmatizing attributions (Flanagan \& Davidson, 2009). Similarly, exposure and familiarity would seem relevant at a neighborhood level given findings that adversarial positions about mental health programs moving into neighborhoods decline after the program is established (Arens, 1993; Wahl, 1993). Finally, within certain racialized and minority ethnic groups, community member perceptions are conceptualized within a collectivist framework, wherein the community as a whole experiences the stigma and discrimination alongside the person with the mental illness. This has been noted as both supportive and a potential source of stress for persons with mental illness (Leamy, Bird, Le Boutillier, Williams, \& Slade, 2011).

In part, the importance of these lines of investigation lies in the emphasis upon constructs of "community" and "community participation" in practice and policy dialogues (Mental Health Commission of Canada, 2012; WHO, 2013). While often invoked, community is much less often defined and it is much more complicated than would be suggested in its wide ranging and superficial usage. In disability literatures community participation is seen as an individual's social and emotional connections to and within a place, created through personal meanings (Royce-Davis, 2001; Walker, 1995). Community itself has been conceptualized as having 
physical, social, and psychological elements that can be defined and experienced at individual, social and cultural levels (see Royce-Davis, 2001, and Yanos, Felton, Tsemeris \& Frye, 2007 for reviews). Other dimensions of community receive greater attention outside of the disability literature, ${ }_{2}$ such as specific neighbourhood and city characteristics and political and economic aspects of community and-participation therein-(Manzo \& Perkins, 2006). These nuanced conceptualizations of community stand in contrast with what are arguably narrow bands of inquiry in much of the mental illness literature. This literature has concentrated largely on frequency counts of the use of community spaces or experiences associated with community participation (e.g., employment, education) (Baumgartner \& Herman, 2012; Royce-Davis, 2001). Such conceptualizations, while relevant, largely overlook social and psychological aspects of community. This is an important omission given that in client descriptions of the recovery process, the major emphasis lies in these areas rather than the amount of time spent engaged in activities such as employment (Davidson, 2003).

The present study is intended to move this area of inquiry forward by concentrating, qualitatively, on the experiences of a broad range of individuals associated with the mostaccessed community resources for diverse, urban-dwelling individuals with psychosis. These individuals, the Imams, librarians, coffee shop clerks, community service workers, convenience store clerks, and the like, form much of the day-to-day social contact of people with SMI who are often otherwise socially isolated (Davidson et al., 2001). In this regard this study is amongst the first to undertake this level of examination. The emphasis in this study is breadth in mapping out the perspectives of these key community stakeholders. The intent is to assess key issues that might be brought forward in future work which that could better attend to depth of inquiry with 
specific subgroups as well as and the nuances of interactions in these community spaces. In this regard this study is amongst the first to undertake this level of examination.

\section{Methods}

\section{Overview}

This scan of key community stakeholder perspectives regarding mental illness and how it is understood in their neighborhoods and spaces was undertaken through qualitative interviews in their workplaces. The focus was upon downtown neighbourhoods in a large urban centre in which there is both-a high concentration of low cost and supportive residences and shelters occupied by people with severe mental health and addictions challenges-as well as and a range of relevanthealth and social services. Through a grounded theory-informed design these interviews were intended to map out people's understanding of mental illness as it relates to their position in the community to better inform the understanding of these community spaces and their associated resources and barriers. Questions focused on their participants' general beliefs and experiences with respect to mental illness, associated experiences with their work spaces and neighbourhoods, and their understanding of what is needed to improve the situation if they perceived challenges. A limitation lies in the reliance upon the term 'mental illness' and the fact that if and how it becomes visible or divulged to these community members is likely variable. Further, the design of this study did not allow for the parsing out of the dimensions of inclusion that might attend other stigmatized identities, the process of labeling and implications of labeling for responses, and the observation of behaviours which might differ from participant reports about their behaviours. It does, however, serve as a starting point for conversations in relation to 
beliefs and experiences connected with mental illness in urban community contexts that are important in theshape experiences of community, inclusion, and recovery for people with SMI.

\section{Study Setting and Participants}

This study took place in five diverse inner-city neighborhoods in the downtown core of a large Canadian city. The sampling of participants was comprised of two stages. First, we had community participants recommended to us by participantsindividuals taking part in a complementary study of community participation among East Asian, South Asian, African Caribbean, and White European-origin individuals with psychosis (ref. withheld for blind review Kidd et al., 2016b). We asked these individuals to identify community organizations and individuals, in both profit and not-for profit/service sectors, with whom they have had significant interactions. We sought out people and organizations that were regularly accessed or, if access had been limited but significant, the contact was significant (e.g., a discriminatory space). We then employed a purposive sampling strategy to build from these recommendations in the form of broadening the base of participants from a category (i.e., seeking out more representatives from religious organizations) or adding categories that appeared relevant to conversations about discrimination and inclusion (e.g., police). We sought to maximize diversity while continuing to sample until saturation was achieved across groups of participants. Participants received an honorarium of $\$ 25$ and the study was approved by an institutional Research Ethics Board.

\section{Method of Inquiry}

Interviews were pre-arranged through phone call or email, or were done upon initial contact in a space (e.g., dropping in on a convenience store clerk). Because of the nature of the 
interviews (ranged from brief, informal conversations with business employees while they were working to 1.5 hour conversations) and the sensitivity demonstrated by some participants regarding their having any personal data collected, we collected the individual's setting and employment information only. Consent was obtained verbally and the study was described as an effort to understand community and community participation in downtown neighbourhoods as they relate to mental illness. Interviewers identified themselves as research staff/students from the tertiary psychiatric academic health sciences centre which hosted the study. This site is well known to the public, particularly in the neighbourhoods of focus.

A semi-structured qualitative interview was developed from community theory literatures (Aubry \& Myner, 2009) and was done 1-1 in the work setting of the interviewee. Interviews began with broad questions such as "What is the community like around here?" and moved to questions about who accessed their service or business and the kinds of interactions that generally take place. The focus then moved on to questions about mental illness "How do you think people with mental illness are treated in our society?" with a movement towards discussing impressions of mental illness and associated interactions as they relate to their space of work. We made an effort to employ a narrative framework, seeking out stories and experiences that underlie beliefs. Interviewing and data analysis were undertaken by a Sociologist, Public Health and Counselling Psychology graduate students, and a Clinical Psychologist. All interviews were audio-recorded and transcribed verbatim with field notes used to capture observations and informal interactions.

\section{Data Analysis}


All field notes and transcribed audio recordings were analyzed using the coding strategy articulated by Charmaz (2003). While the goal of this study was not the development of theory, this analysis strategy was chosen for its rigor. First, common themes/categories were derived through an open coding process. Second, there was a movement toward developing conceptual categories. Throughout the above process memos were used to document and inform the analysis process. Several steps were taken to maximize rigor in the analysis and to establish the credibility and trustworthiness of the findings. First, we obtained in-depth narratives, carefully took field notes documenting observations and reactions, and coded verbatim transcripts line by line. Second, we engaged participants in discussions about the emerging categories and themes as described above. Nearly all participants took part in this iterative process as informal analysis early in the study and formal analysis later led to a more nuanced inquiry, the checking of emerging themes, and ideas about others who could be recruited as the study progressed. These more specific 'checking' questions were employed towards the end of interviews so as to not influence more open ended narratives. We did not elicit any significant disagreements regarding emerging themes but, rather, prompted or deepened conversations as people considered topics they hadn't mentioned (e.g., gentrification) and considered the responses of participants from other community sectors. This process deepened the analysis of the core emergent constructs and helped ensure better alignment of our understandings of the themes with the participants' meanings. Third, we conducted detailed reviews of the code structure by the research team (checking categories against original text; reviewing all coded text; having dialogue and feedback about coding structure). Preliminary findings were also reviewed over the course of the study by an advisory group of individuals with lived experience of mental illness. This input assisted in refining the inquiry and critically considering the findings. 


\section{Overview}

Despite the highly diverse group interviewed, there was a common structure to their narratives about mental illness-which included three major themes. Most participants began their responses by positioning mental illness in relation to themselves and their role and place in the community. This assignment of meaning took several forms - all of which shaped, in their $\underline{\text { narratives, how they thought about inclusion as it related to mental illness, how they talked about }}$ it with others, and how they interacted with people believed to have a mental illness. The positioning of mental illness was done through descriptions of personal experiences (themselves or people they knew), First, through both narratives about experience and summary statements, participants described their understanding of mental illness. Embedded in this broad theme were subthemes that included their personal experiences as they related to mental illness, comparison 
8

between their perspectives and those they understood to be held by society at large often in a context of gentrification, and descriptions of thethe_value system through which they framed their understanding of mental illness-(e.g., service ethos, religion, culture). The second major theme topic involved descriptions of how they attempted to create welcoming and inclusive environments that addressed the needs and experiences of people that they understood to have mental health challenges. The third and final themeFinally, considerable discussion was focused upon wolved descriptions and understandings of situations that were seen as challenging as a function of mental illness in their spaces of work and epinions about what is and is not available by way of response. Throughout the descriptions of the findings below we highlight thematic differences as a function of respondent type and use bold font to identify subthemes.

\section{Understandings of Positioning Mental Illness: "I think a lot of people have problems.} No one gets away.”

Whether holding public service or business-oriented roles, participants emphasized the importance of their "understanding" how mental illness emerged and affected people's lives. This was often described as appreciating the "resilience" of people with SMI and the challenges that they faced. Herein was the assumption that it is not the person that is judged and perhaps rejected. Rather, culpability was separated from the person and placed on the mental illness - or by extension the "lack of what they had as a kid" or similar determinant. Language was used carefully here. For example, "understanding" was emphasized over more superficial conceptualizations such as contact, and challenging situations emphasized as being "accepted" rather than "tolerated." This type of framing was described as being important in the cultivation of patience and tolerance in times when "the mental illness gets a hold." 


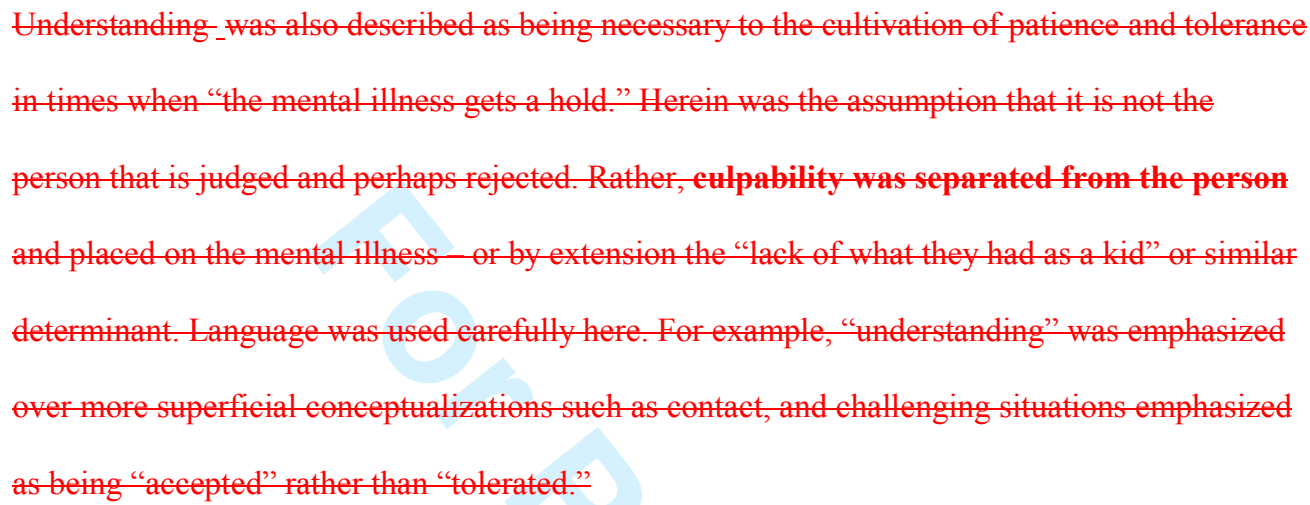

"You understand that it's not necessarily them as much as their mental health issue that's their problem and once people are calm, a lot of times they're completely different than when they were having their outburst or their crisis period...They're survivors and they're coping, but they could still have a bad day"

Another way in which mental illness was toeated-positioned was in reference to their own mental health challenges. Generally a narrative that was less apparent among service providers, this theme served the function of narrowing the divide between the participants and individuals facing mental health challenges__ cultivating a degree of empathy. For those who emphasized direct experience, the point was made that those who seem visibly mentally ill are only a small proportion of the much larger group of people who are affected.

"I had a sense of that [what changed his perspective regarding people with mental illness] when I got laid off in 2005 and it took me $2 \frac{1}{2}$ years to find another job. I 
finally found this job, which is not even what I was trained for. But for $2^{1} \frac{1}{2}$ years I wasn't a contributor to society after having been that way for 30 years...there was a sense of lack of worth and I think to a large degree people here [customers with mental illness] see that every day. I'm not contributing_, I don't have...I take up space. I'm a waste of space."

This sense of relating with the marginality of people with mental health challenges extended to commentary about participants feeling themselves alienated by rapidly gentrifying neighborhoods. While not notably varying as a function of specific neighborhood, this was particularly salient for those most at risk of gentrification. Those operating low cost, nonfranchise businesses such as coffee shops with radically increasing rent, near to blocks demolished to build condos, and facing the incursion of franchises whichthat are difficult to compete with.

“And I walk home on a good summer or spring evening and when I get to [the financial district], the intensity of those super achievers pushes everything aside, including me because I'm not dressed right."

For others, most notably spiritual leaders and the staff of some franchise businesses, the perspective from which mental illness was framed-positioned was less one of individual perspective and more one of culture - be it service ethos or collective belief grounded in religion. The spiritual leaders interviewed suggested that a medical framing of mental illness | “isn't serving this as well as we want it to." These individuals suggested emphasized the 
importance of a spiritual overlay to mental health concerns, which required a different type of engagement. For example, a Tibetan Buddhist monk, said that in his order everyone is considered equal and it is his mission in life to "embrace the marginalized and the poor." Franchised business employees described a service ethos in which all customers are to be provided good service - in this manner the identity of mental illness is superseded by their identity as a valued customer.

\section{Overall, theThe majority of those interviewed made an effort to locate themselves in} egalitarian relationships with marginalized people. However, there were exceptions. For example, while still aligning with the view that illness needs to be separated from the individual, one service provider noted that there is "attitude" and there is "illness" and "the staff here don't need to be abused by anyone." This participant suggested that there were grounds at times to exclude people while maintaining that it was not based upon mental illness but something more fundamental to the person. Another service provider described the perception of sharp differences between themselves and those served. This person felt that they were a "paid friend" and that the drop-in space where they worked felt like "a soap opera" or a "reality show." In this vein one other service provider suggested that her position "in the field" as someone who knows "much more" than the average person left her more uncomfortable around people with mental

illness. This stands in sharp contrast with other participants whose-who framed their understanding and contact as resulting in less fear and avoidance. was described as reducing fear.

“When I personally see somebody who's walking down the road talking to himself- I cross the street - and I've been doing this [working in the mental health 
field] for 25 years...I know people who are mentally ill are unpredictable. They don't follow the same cues that we do."

The police officers that were interviewed, unlike other community stakeholders, described their experiences with people with mental illness as being "skewed." They noted that | they "hadn't had any really good experiences with mental health patients" and that they generally engaged people with overt mental health issues when they were called to enforce the law.

"We're just unfortunately always there for a bad times right? We're always there when they're not having a good time. We're not there when it's your birthday or you've just graduated...it's definitely skewed."

Many participants also contrasted their perspectives and views with those of the general public as a way of positioning themselves - highlighting difference from a public that generally "lacks empathy and understanding" and is "afraid." Others framed themselves as a part of a broader movement in society in which mental illness is "talked about more in everyday life" and where there are "opened doors for understanding." In this light some evertly referenced improvements in this area as building fromdiscussed the benefits of public awareness initiatives such as the Bell "Let's Talk" campaign that encourages more open acknowledgment of mental illness, features public figure disclosures of same, and seeks to reduce stigma. 


\title{
2. "You give them good service. You treat them good so they like to come here."
}

For business owners, a central theme was one of seeking to create a positive experience for their customers - creating a comfortable, welcoming and safe space.

\begin{abstract}
"You give them good service, you treat them good so they like to come here, they don't only want to come for food they come here, they sit, they talk ... they sit here, they like to sit here."
\end{abstract}

This effort was not limited to their own one-on-one interactions, but tended to fall along the lines of wanting to have a social tone of comfort which lent to a more positive work and personal experience and greater profits. In some instances this effort went beyond the bounds of good business but extended to specific efforts to help people. One coffee shop owner described giving odd jobs to some individuals in return for food and coffee when they had no money, and having had a customer donate to them a $\$ 100$ credit which impoverished people could use and pay back when they could. This credit was never abused according to the business owner.

\footnotetext{
"I think he [person known to have a mental illness] was drunk so somebody just hit him and he fell down and nobody was helping him. I was cooking and I see him and I knew this is my regular customer so I stopped cooking, I go outside and bring him water and asked him [if he was okay], he said I'm a little bit sick today...so I give him water, tea and he just swallowed it and then he go."
} 
Spiritual and service organizations similarly described active efforts to make people feel welcome and less isolated. For example, one spiritual leader described making "a point to go talk to them - I will make a point of going and shaking their hand, welcoming them on Sunday.” Community service organizations described creating a range of venues, from sharing meals to groups organized by gender and ethnicity that gave people "a nudge out of [their] isolation." They described how people might be initially "afraid" of being in close proximity to others and are quiet but that “doesn't last long...they start to chat and I absolutely love it.” Most mental health-focused service providers did not address actions to create inclusive spaces to any great extent, other than one noting that a "calm and stable environment, not something that is changing all of the time" is needed along with "a basic structure." It was asserted that without these provisions "they don't feel comfortable, they feel scared."

Finally, a very common theme was the need to not "rush" and to be patient. Business owners in particular described how in "this busy world" there is a need to slow down with people with severe mental illness, who might require multiple repetitions of questions or "forget what they order and get confused at times".

\section{3. "Asking them to leave or asking them to calm down"}

A major component of the narratives of all participants was the question of how to respond to behaviours of people that made others uncomfortable - whether framed as merely "peculiar" or overtly threatening and aggressive. This was framed by most as a "balancing act." At varying degrees participants did not want "to make it a police issue" due to the disruption of having the police arrive, police often arriving too late to address what are often 
brief incidents, and feeling badly for the person who they saw as needing services rather than being arrested. This was one of the few areas in which some participants made a distinction between mental illness and addictions. When describing problematic situations of this nature, several described people with severe addictions as presenting the biggest problem or ${ }_{2}$ more broadly, people with mental illness "when" they are abusing drugs or alcohol.

"You have to balance between protecting the store and the customers and the business and at the same time try not to make it a police issue...but for me if they come in and they're just sitting in a corner quietly yammering to themselves or whatever, then you can just leave them alone...there aren't enough services out there and certainly people who need it are not always the ones who are getting it."

Most of the business owners described negative instances, such as people yelling and damaging property, as occurring much less often than positive interactions with people thought to have a mental illness. Across business and service settings, there was a general impression that a strongly negative response tended to unnecessarily escalate situations.

\begin{abstract}
"One negative experience was like one customer, I served him food and then he asked me for water, after that we bring it and he throw it in my face. He forgot that he ask me for water and instead he just threw water [the] in my face. [Did you call the police?] Oh no not like that because we know they are disabled so we try to be polite and try to be nice because we know if we treat them badly then they're going to be more worse."
\end{abstract}


Service provider narratives tended to be framed along the lines of providing "latitude" but drawing the line at what was considered a breach of safety for staff or other clients - noting that others might be traumatized and being particularly sensitive to aggressive behaviour. The question of "banning" from an organization was somewhat contentious, with some participants noting that banning people led them to come back even angrier while others described temporary or in some instances permanent bans as necessary to safety.

Other than community and mental health service providers, many felt at a loss about how to respond to challenging behaviours that they attributed to mental illness-feeling that a police response conflicted with their values and what they believed was appropriate to what was happening with the person in question. This was framed both in broad terms in settings such as retail stores but also framed culturally as was the case for several of the spiritual leaders interviewed.

\begin{abstract}
"We had an incident where this woman, the only reason she was in the store was to get her children out of the store...but her children aren't there. And so the one shift supervisor was holding the door open going along with this and, you know, 'come on guys you all gotta go'. And, I mean, it breaks my heart really, you know, and I don't feel it is necessary to call the cops for these specific people. That's what makes me reluctant to call the cops [be]cause they don't need to go, they need help. And I've seen the police officers, they're fine with them, they're
\end{abstract}


assertive, they're not so much gentle but they do get their point across and they get them out of the building."

"[In the mosque a] challenge arises when there is a conflict some people they don't have knowledge, they don't understand, but they just become more emotional, they say 'why you call police here?'. [By calling the police] you create division in the community, because people don't like that police come, sometimes police come, they enter to the carpet with their shoes [a sign of great disrespect], and the way they take the person...it's not nice sometimes...they may have strong interventions, so we try and avoid, and in our constitution actually we said if after many effort we try to stop any fight and if he does not stop, we will call police, not to take him to jail, only to make the environment of the mosque or the prayer hall peaceful."

While most viewed the police as doing the best they could with being understanding while still enforcing the need for a person to leave a space, there was a general sense that police and security responses tended to be excessive - "The next minute 7 police in flack jackets arrive for really what was just an idle threat." The police, in turn, felt that the majority of mental healthrelated calls that they received were not a good use of their time, describing how they might be forced to address someone who had publicly urinated when they hear "on the radio a call about someone being stabbed two blocks over." They described how gentrification, in their opinion, had greatly increased the number of calls that they felt were more the work of mental health professionals than the police. 


\section{Context and Absent Voices}

1

There were some contextual points that received little attention in the participant responses but were readily observed by the interviewers. For example, in convenience stores interactions tended to be very brief and undemanding and many store clerks described not noticing or caring if a person has a mental illness so long as they are a paying customer. Settings in which interactions were longer and more complicated (e.g., restaurants, drop-ins) were where an analysis regarding mental illness and challenging experiences were more readily elicited. As well, it had been the intent of this study to speak with community members who were described as discriminatory or abusive-by other community members or the people with SMI. Going to these places we found that some refused to be interviewed and those who did tended to describe their efforts and attitudes as inclusive despite what had been reported by others. Finally, this study did not fulsomely address the self-concepts and identities of the respondents. While clearer in some instances (e.g., implications of they themselves having had a mental illness; spiritual leaders having a clear mission with regards to people seen as marginalized and disadvantaged), this was less the case for others. The implications of these narratives in shaping self-concept was unclear for many as was also the case for contexts with a more ambiguous connection to marginalized people (e.g., retail businesses). As noted in Goffman's seminal work The Presentation of the Self in Everyday Life (1959) and verified in dozens of studies since (Schlenker, 2012), the self is constructed and negotiated in these very kinds of interactions. 
The resulting qualitative analysis of the interviews with a diverse group of 94 participants operating spaces and providing services in downtown neighborhoods revealed three eore-themes. The first, and foundational theme, involved their sharing opinions and experiences in relation to how they understood positioned mental illness in relation to themselves, their space, and their activities. These conversations framed how they described responding to mental illness as an general issue and their interactions with the people that they perceived as having a mental illness.

\section{This positioning of mental illness, for most, provided the context within which participants}

described their effortsDescriptions of these interactions formed the second theme, which involved a large degree of agreement about how most described efforts to create welcoming and inclusive environments. The third theme, in turn, focused on their descriptions of responses to challenging situations that they associated with mental health issues. 
The finding that the understanding or positioning of mental illness is critical to community member views on what their response should be fell in line with previous studies of stigma (Angermeyer et al., 2003). Unlike previous work that has emphasized specific labels or types of mental illness in determining response (Pescosolido, 2013), these narratives emphasized the importance of where responsibility for the illness and its outcomes were located. Positive responses and less stigmatization were connected with finding blame in "poor pasts" and locating the problem in "the illness" rather than the person. These findings echoed work that has noted that a lower desire for social distance is associated with illness being viewed as a result of challenging childhoods (Angermeyer et al., 2003). It was of note that "illness" in this context was very broadly used and, unlike much of the current academic and clinical discourse, did not specify or emphasize biological explanation.

Beyond considerations of etiology and locating the source of the problem, varying degrees of sympathy and empathy were described as arising from the consideration that the majority of the time mental illness is not visible and not important and that people need to be considered as individuals rather than illnesses. Furthermore, many described a respect for the resilience of those affected. Empathy was particularly evident in the narratives of participants who described a lived experience of mental illness - be it that of a family member or friend or themselves. This seemed to greatly reduce the degree of separation fromperceived difference and distance from the issues that attend mental illness, with participants identifying with the marginality and isolation that attends mental illnessmany of those affected experience. IndeedFurthermore, participants many-shared the perception that it was easier to have conversations about mental illness due to large scale anti-stigma campaigns, which stands in 
contrast to studies that suggest that stigmatization is not decreasing (Parcesepe \& Cabassa, 2013)

and that anti-stigma campaigns have a limited impact (Read, Haslam, Sayce \& Davies, 2006).

For those operating small businesses in rapidly gentrifying neighbourhoods, these narratives went further to carry a tone of being marginalized together and being able to relate with "not fitting in" along socioecomic and cultural lines. This latter point is very relevant to urban settings where, increasingly, gentrification is leading to individuals with mental illness moving to more resource-dispersed inner suburbs (Metraux, Brusilovskiy, Prvu-Bettger, Wong, \& Salzer, 2012).

It was in moving from positioning mental illness to describing responses that differences were observed in the narratives in helping profession roles as compared with those of business owners and other professional roles (e.g., spiritual leaders). Service providers described lived experience with mental illness to a lesser extent and ${ }_{2}$ in contrast with evidence that contact with individuals with mental illness reduces stigma (Stuber et al., 2014), some described how their greater amount of professional "knowledge"_made them more aware of dangerousness and better able to parse out "attitude" versus "illness." This finding resonates with work suggesting that strong stereotypes persist among service professionals in reference to severe mental illness (Stuber et al., 2014).

Interestingly, the police officers interviewed were more cognizant about the bias of their perspective, noting that they are only called when there is a problem and this "skews" their beliefs. Recently, more nuanced work with implications for parsing out factors that increase or 
reduce such biases has focused on the schemas of police officers, examining perceptions of difficulty and danger in calls as a function of how individuals present. Factors such as perceived intoxication, poor hygeine, younger age and male gender along with indications of resistance all have been found to enhance negative responses by police (Watson, Swartz, Bohrman, Kriegal, \& Draine, 2014).

In several contexts the conversation about cultivating welcoming spaces emerged at a more cultural level. This included franchises that described the overridinga service mission to provide polite, warm, and welcoming spaces for all customers 2 and religious organizations that applied a framework of love, respect, and support for all (e.g., "they are all my brothers"). This finding resonated with service development research describing efforts to advance recoveryoriented care in psychiatric hospitals where a franchise-like, service mission approach is being considered helpful (Bromley, 2012). While on the surface such values-driven perspectives would appear positive and conducive to cultures of inclusion, a potential caveat might be drawn from research examining organizational approaches of 'color blindness' as a way of addressing racism. Notably, inclusion in such contexts resulted less from assertions of this philosophy but, rather, actual diversity in the workforce. In such settings racism can still be very present thoughifmore subtle and reframed in more acceptable terms-(Apfelbaum, Norton, \& Sommers, 2012).

Outside of considerations of service or religious "missions", other businesses applied the simple framework of maximizing profit, noting that the money of people with mental illness is worth the same as everyone else's and unpleasant interactions tend to drive away customers. In 
contrast, mental health service provider narratives tended to emphasize stability over inclusion. This included descriptions of how "calm", "stable" and "structured" environments are less stressful for people with mental illness. Indeed, this theme echoed the irony of custodial care that without some stress and challenge people cannot learn from mistakes and challenges to make greater strides in recovery including community participation (Slade, 2009). Calm, stable, and structured environments might well in fact be cultivating further marginalization.

Finally, a considerable amount number of participant narratives were dedicated to describing challenges that can arise in interactions with people viewed as having mental health concerns. The more common challenge was the need to cultivate patience, recognizing that some customers and service recipients at times might complete financial transactions slowly, require multiple repetitions of requests and instructions, and can be forgetful and distracted. The more rare demand came with managing behaviours that were disturbing for other people (customers or service recipients) or that might damage property. Here almost all participants highlighted that taking an authoritative stance or involving security services were far less effective than polite, personalized requests with a welcome back once the person is less distressed. All participants highlighted dissatisfaction with calling for a response from the police. While these narratives ranged from descriptions of police in a very positive light as being firm but very respectful to highly excessive (arriving in "flack jackets"), all agreed that a better systemic response is needed. The police officers concurred with this view, considering the majority of mental illness-related minor disturbance calls to be a poor use of their time. Indeed, they reflected upon how gentrification and changing expectations about neighbourhood aesthetics were greatly increasing the number of minor disturbance calls. This likely speaks to the lack of appropriate mental health 
services at a systems level and factors such as stigma and shortcomings in training that escalate conflict between the police and people experiencing mental health crises (Mental Health Commission of Canada, 2011). Regarding the latter point, there would seem to be some promise in developing specialized response teams among police officers with the specific mandate to respond to mental health calls. In contrast with the findings of this study, officers in such programs may be more confident in their ability to respond to such calls and feel that their work is important and effective (Bonfine, Ritter \& Munetz, 2014). This would align with the benefit to people with SMI with fewer unnecessarily ending up in criminal justice systems and, possibly, fewer tragic outcomes with ineffective engagement leading to the use of deadly force.

This study had several limitations. These include a reliance upon self-report interviews Formatted: Tab stops: Not at $0 "+0.5^{\prime \prime}+$ $2^{\prime \prime}+2.5^{\prime \prime}+3^{\prime \prime}+3.5^{\prime \prime}+4^{\prime \prime}+4.5^{\prime \prime}+5^{\prime \prime}+$ and the likelihood of varying degrees of impression management (i.e., even when going to $5.5^{\prime \prime}+6 "+6.5^{\prime \prime}+7^{\prime \prime}+7.5^{\prime \prime}$ spaces viewed as discriminatory the narratives tended to be inclusive) nor does it allow for an $\underline{\text { examination of how described beliefs and experiences might not fully map onto private beliefs }}$ and actual behaviors. This study also did not fulsomely unpack how identity and self-concept was reflected in and shaped by these narratives about mental illness - be it as a function of public $\underline{\text { role, individual psychology, or culture. A close examination of such dynamics might prove very }}$ informative in identifying points of leverage through which interventions to reduce stigma and enhance inclusion might be improved. and, more subtly, the manner in which the described beliefs and experiences might not fully map onto private beliefs and actual behaviors.

Furthermore, this study relied upon the use of the term "mental illness" to describe the focus of the study and the inquiry in the interviews. While time was spent exploring participant understandings of mental illness, this study was not able to fully explore the nuances that attend 
mental illness in these settings (i.e., disclosed or not; visible or not and what leads to a labeling of 'mentally ill' behavior) nor did it examine intersections with other stigmatized identities. Furthermore, the study took place in downtown neighborhoods in a single Canadian city and there may be concerns regarding transferability.

Despite these limitations, and the emphasis upon breadth in a preliminary mapping out of these key community perspectives, this study highlighted a number of issues and processes that have to date had minimal attention in the academic literature. This is an important area of inquiry given the heavy emphasis upon "community" as a key resource in mental health reform and recovery and the importance of informal community contacts in reducing isolation among individuals with SMI (Davidson et al., 2001). These findings suggest the potential benefit of providing resources to people and spaces in communities that are routinely accessed by people with SMI. This might involve learning from examples of highly inclusive spaces, work that we are pursuing with the use of film as an education tool

(https://www.porticonetwork.ca/web/community-reconsidered/action/videoAppendix 1 - omitted to facilitate anonymous review - depicts two restaurants widely regarded as very inclusive, how they came to be so, and what an inclusive framework brings to such spaces). Indeed, these findings suggest the potential benefit of fostering cultures of inclusion, such as those cultivated by religious organizations and franchises albeit with the caveats noted above about representativeness among employees being more important. Furthermore, this work highlighted the clear inefficiency and inadequacy of traditional policing as a response to the majority of mental health-related challenges - an issue all the more salient in gentrifying neighborhoods that may be less tolerant of visible manifestations of poverty and mental health challenges. Finally, 
this work highlights how mental health service providers may have the furthest to come along in truly adopting holistic inclusive stances and grappling with the risk taking that is necessary for recovery. This might contribute to conversations about the potential benefits of a greater integration of peer supports in care contexts, as individuals who may be more aware of and sensitive to the lived experience of community of people directly affected by mental illness. Directions for future research would include employing greater depth in considering specific subgroups of community stakeholders, social geographic analysis that might consider difference as a function of space and location (increasingly relevant inner suburban settings, rural settings), consideration of intersecting identities (e.g., sexual and gender minority, racialized, cultural, poverty), and more intensive ethnographic and behavioural analysis that might better separate the nuances of observed versus described responses and experiences. 


\section{References}

Angermeyer, M., Beck, M., Matschinger, H. (2003). Determinants of public's preference for social distance from people with schizophrenia. Canadian Journal of Psychiatry, 48, 663668.

Apfelbaum, E. P., Norton, M. I., \& Sommers, S. R. (2012). Racial Color Blindness Emergence, Practice, and Implications. Current directions in psychological science, 21(3), 205-209.

Arens, D. A. (1993). What do the neighbors think now? Community residences on Long Island, New York. Community Mental Health Journal, 29(3), 235-244.

Aubry, T., \& Myner, J. (2009). Community integration and quality of life: A comparison of persons with psychiatric disabilities in housing programs and community residents who are neighbours. Canadian journal of community mental health, 15(1), 5-20.

Bonfine, N., Ritter, C., \& Munetz, M. R. (2014). Police officer perceptions of the impact of crisis intervention team (CIT) programs. International journal of law and psychiatry, 37(4), $341-350$

Bromley, E. (2012). Building patient-centeredness: Hospital design as an interpretive act. Social Science \& Medicine, 75(6), 1057-1066.

Charmaz, K. (2003). Grounded theory. Qualitative psychology: A practical guide to research methods, 81-110. 
Corrigan, P. W., \& Watson, A. C. (2002). Understanding the impact of stigma on people with mental illness. World Psychiatry, 1(1), 16.

Corrigan, P. W., Larson, J. E., \& Ruesch, N. (2009). Self-stigma and the "why try" effect: impact on life goals and evidence-based practices. World Psychiatry, 8(2), 75-81.

Davidson, L., Haglund, K. E., Stayner, D. A., Rakfeldt, J., Chinman, M. J., \& Kraemer Tebes, J. (2001). " It was just realizing... that life isn't one big horror": A qualitative study of supported socialization. Psychiatric rehabilitation journal,24(3), 275. Reference withheld to facilitate blind review.

Flanagan, E., \& Davidson, L. (2009). Passing for normal: Features that affect community inclusion for people with mental illness. Psychiatric Rehabilitation Journal, 33, 18-25.

Goffman, E. (1959). The Presentation of the Self in Everyday Life. New York: Double Day.

Kidd, S.A., Howison, M., Pilling, M., Ross, L., \& McKenzie, K. (2016a). Severe Mental Illness + among LGBT Populations: A Scoping Review. Psychiatric Services, Online First http://dx.doi.org/10.1176/appi.ps.201500209.

Formatted: Font: Not Bold Formatted: Line spacing: Double

Field Code Changed

Formatted: Font: Times New Roman, 12 pt 
Kidd, S.A., Frederick, T., Tarasoff, L., Virdee, G., Lurie, S., Davidson, L., Morris, D., McKenzie,

\section{$\underline{\text { K. (2016b). Locating community among people with schizophrenia living in a diverse }}$}

urban environment. American Journal of Psychiatric Rehabilitation, In Press.

Krajewski, C., Burazeri, G., \& Brand, H. (2013). Self-stigma, perceived discrimination and empowerment among people with a mental illness in six countries: Pan European stigma study. Psychiatry research, 210(3), 1136-1146.

Leamy, M., Bird, V., Le Boutillier, C., Williams, J., \& Slade, M. (2011). Conceptual framework for personal recovery in mental health: systematic review and narrative synthesis. The British Journal of Psychiatry, 199(6), 445-452.

Mental Health Commission of Canada. (2011). A Study of How People with Mental Illness Perceive and Interact with the Police. Mental Health Commission of Canada. $\underline{\text { www.mentalhealthcommission.ca }}$

Mental Health Commission of Canada. (2012). The Mental Health Strategy for Canada. Mental Health Commission of Canada: Calgary, AB.

Mestdagh, A., \& Hansen, B. (2014). Stigma in patients with schizophrenia receiving community mental health care: a review of qualitative studies. Social psychiatry and psychiatric epidemiology, 49(1), 79-87.

Metraux, S., Brusilovskiy, E., Prvu-Bettger, J. A., Wong, Y. L. I., \& Salzer, M. S. (2012).

Geographic access to and availability of community resources for persons diagnosed with severe mental illness in Philadelphia, USA. Health \& place, 18(3), 621-629.

URL: https://mc.manuscriptcentral.com/ajpr Email: stephanie.sangsterlanteri@yale.edu 
Parcesepe, A. M., \& Cabassa, L. J. (2013). Public stigma of mental illness in the United States: a systematic literature review. Administration and Policy in Mental Health and Mental Health Services Research, 40(5), 384-399.

Pescosolido, B. A. (2013). The Public Stigma of Mental Illness What Do We Think; What Do We Know; What Can We Prove?. Journal of health and social behavior, 54(1), 1-21.

Read, J., Haslam, N., Sayce, L., \& Davies, E. (2006). Prejudice and schizophrenia: a review of the 'mental illness is an illness like any other' approach. Acta Psychiatrica Scandinavica, 114(5), 303-318.

Schlenker, B. (2012). Self-Presentation. In M.R. Leary \& J.P. Tangney (Eds.) Handbook of Self and Identity. (pp. 542-570). New York: Guilford.

Formatted: Indent: Left: 0 ", First line: $0 "$

Slade, M. (2009). Personal recovery and mental illness: a guide for mental health professionals. Cambridge University Press.

Stuber, J. P., Rocha, A., Christian, A., \& Link, B. G. (2014). Conceptions of mental illness: Attitudes of mental health professionals and the general public. Psychiatric Services.

Wahl, O. F. (1993). Community impact of group homes for mentally ill adults. Community Mental Health Journal, 29(3), 247-259.

Watson, A. C., Swartz, J., Bohrman, C., Kriegel, L. S., \& Draine, J. (2014). Understanding how police officers think about mental/emotional disturbance calls. International journal of law and psychiatry, 37(4), 351-358. 
